\title{
Perancangan Sistem Informasi Calon Wisudawan Universitas Advent Indonesia
}

\author{
Adam William Yordan Sihotang*1, Elmor Benedict Wagiu² \\ 1,2Fakultas Teknologi Informasi, Universitas Advent Indonesia \\ e-mail: *1adamsihotang3@gmail.com, 2elmor@unai.edu
}

\begin{abstract}
Abstrak
Pemanfaatan teknologi saat ini sangat banyak digunakan di kalangan masyarakat untuk mendukung kegiatan sehari-hari. Dunia pendidikan merupakan salah satu bidang yang terpengaruh terhadap perkembangan teknologi tersebut. Kegiatan belajar mengajar saat ini sudah mengadopsi alat-alat teknologi informasi. Tidak hanya itu, kegiatan lain dalam proses akademik pun tidak luput dari perkembangan teknologi tersebut, yaitu penggunaan sistem informasi dalam proses administrasi perkuliahan. Universitas Advent Indonesia adalah salah satu institusi pendidikan yang sudah menggunakan sistem informasi dalam proses administrasi akademik. Akan tetapi masih ada beberapa bagian dari akademik tersebut yang belum menggunakan sistem informasi, salah satunya adalah proses administrasi pengurusan wisuda. Tujuan penelitian ini adalah agar sistem informasi yang dibangun dapat membantu para mahasiswa dalam proses pengurusan hal-hal yang berkaitan dengan pendaftaran wisuda yang selama ini menggunakan formulir berupa kertas. Metode penelitian yang digunakan dalam penelitian ini adalah Metode SDLC (Software Development Life Cycle). Sedangkan kesimpulan dari penelitian ini adalah, (1) sistem informasi calon wisudawan ini dibuat dengan menggunakan Bahasa pemrograman PHP (Hypertext Preprocessor) dan MySQL sebagai databasenya. Adapun fungsi yang ditawarkan pada sistem informasi ini adalah halaman dashboard, halaman pilih mahasiswa (fakultas), halaman profile mahasiswa, halaman cari mahasiswa, halaman persetujuan calon wisudawan, dan halaman laporan persetujuan calon wisudawan. Sedangkan untuk admin yakni halaman dashboard, profile, form calon wisudawan, notifikasi, ganti password, logout. (2) setelah melakukan pengetesan terhadap sistem informasi ini, didapati bahwa proses pemasukan data calon wisudawan dapat dilakukan dengan baik.
\end{abstract}

Kata Kunci: pendaftaran calon wisudawan, sistem informasi, berbasis web

\section{Design of Information Systems for Universitas Advent Indonesia Graduates}

\begin{abstract}
The use of technology is currently very widely used in the community to support their daily activities. The world of education is one of the fields that is affected by these technological developments. Teaching and learning activities have now adopted information technology tools. Not only that, other activities in the academic process are not spared from these technological developments, namely the use of information systems in the course administration process. Adventist University of Indonesia is one of the educational institutions that already uses information systems in the academic administration process. However, there are still some parts of academia that have not used information systems, one of which is the administrative process for graduation. The purpose of this research is that the information system built can help students in the process of managing matters relating to graduation registration which has been using paper forms. The research method used in this research is the SDLC (Software Development Life Cycle) method. While the conclusions of this study are, (1) the information system for prospective graduates is made using the
\end{abstract}


PHP programming language (Hypertext Preprocessor) and MYSQL as the database. The functions offered in this information system are the dashboard page, the student (faculty) selection page, the student profile page, the student search page, the graduate candidate approval page, and the graduate candidate approval report page. As for the admin, namely the dashboard page, profile, prospective graduate forms, notifications, changing passwords, logging out. (2) after testing this information system, it is found that the data entry process of prospective graduates can be carried out properly.

Keywords: registration for prospective graduates, information system, web-based

\section{Pendahuluan}

Perkembangan teknologi saat ini sangat cepat dan pesat. Dapat dikatakan bahwa kebutuhan masyarakat yang dituntut dengan adanya kebutuhan hidup masyarakat yang mobilitasnya sangat tinggi, sehingga digunakan untuk mencari layanan yang fleksibel dan dapat memanfaatkan waktu dengan baik [1].

Pada bidang tertentu ada bidang pelayanan yang masih dilakukan secara manual, salah satunya pelayanan dalam pendaftaran wisuda yang dilakukan oleh bidang akademik di UNAI. Adapun pelayanan yang berjalan sekarang adalah mahasiswa diharuskan datang ke kantor Biro Administrasi Akademik (BAA) kemudian mahasiswa meminta form pendaftaran wisuda dan mengisi formulir pendaftaran wisuda tersebut yang dimana mahasiswa harus mencari tanda tangan dari Dekan, BAA, BO, Perpustakaan. Setelah mahasiswa melengkapi semua tanda tangan, mahasiswa harus membawa form tersebut dan mengembalikannya ke BAA untuk di input datanya. Adapun proses yang diberlakukan seperti ini kurang maksimal serta akan membutuhkan banyak waktu untuk menyelesaikannya.

Pelayanan informasi merupakan salah satu bagian yang terpenting dari setiap Fakultas untuk dapat memberikan pelayanan yang efektif dan efisien serta selalu update di lingkungan Universitas Advent Indonesia. Untuk itu diperlukan suatu sistem yang dapat memfasilitasi hal-hal tersebut. Melalui aplikasi ini diharapkan mahasiswa akan mendapatkan pelayanan yang baik, serta tidak memakan banyak waktu, karena mahasiswa ketika akan melakukan pendaftaran wisuda dapat mengisi form pendaftaran wisuda secara online.

\section{Sistem}

Sistem adalah semacam aturan yang terdiri atas sekumpulan peranan komponen dengan satuan kegunaan dan peran khusus juga saling berkaitan dan secara bersamaan ditujukan untuk melengkapi sebuah prosedur tertentu [2].

\section{Sistem Informasi}

Sistem informasi adalah kumpulan dari sub-sistem yang saling berhubungan satu sama lain dan bekerja sama untuk mengelola data menjadi informasi yang berguna [4].

\section{Basis Data}

Basis Data (Database) adalah suatu kumpulan informasi yang disimpan di dalam computer secara sistematik sehingga dapat digunakan oleh suatu program computer untuk memperoleh informasi dari basis data tersebut [3].

\section{Metode Penelitian}

Metode yang digunakan untuk perancangan sistem adalah SDLC (Software Development Life Cycle), sebagai berikut: 
Perancangan Sistem Informasi Calon Wisudawan Universitas Advent Indonesia

\section{a. Analysis Requirement}

Pada tahap ini akan diuraikan analisis proses Pendaftaran Wisuda, identifikasi masalah, dan solusi pemecahan masalah.

b. Design

Tahap ini dilakukan untuk menggambarkan panduan mengenai perancangan aplikasi yang akan dibuat secara detail beserta dengan layout yang akan dikerjakan.

\section{c. Coding}

Pada tahap ini penulis akan mengembangkan aplikasi dengan menulis kode terhadap program yang akan dibangun.

\section{d. Testing}

Pada tahap ini akan dilakukan tahap pengujian pada sistem yang telah selesai dibangun.

\section{Analisa Sistem lama}

Berikut ini adalah prosedur dalam melakukan pendaftaran wisuda pada Universitas Advent Indonesia, yaitu:

1. Mengambil formulir pendaftaran calon wisudawan di Biro Administrasi Akademik (diisi oleh mahasiswa yang mengajukan pendaftaran calon wisudawan). Formulir pendaftaran calon wisudawan akademik dikhususkan untuk Biro Administrasi Akademik untuk mendata mahasiswa yang ingin mengajukan calon wisudawan.

2. Setelah mendapatkan 1 lembar formulir yang diberikan kepada mahasiswa yang mengajukan calon wisudawan, harus diisi terlebih dahulu.

3. Berikut adalah langkah-langkah untuk melengkapi formulir pendaftaran calon wisudawan, di antaranya:

a. Pertama, mahasiswa yang mengajukan calon wisudawan diharuskan ke Kantor Keuangan untuk mengurus keuangan semester terakhir agar dapat melunasi keuangan tersebut. Jika mahasiswa masih mendapatkan kredit pada keuangannya, diharuskan untuk melunasinya. setelah itu, mahasiswa harus membayar uang wisuda serta uang senior yang sudah di tentukan.

b. Setelah mengurus ke Kantor Keuangan, mahasiswa akan mendapatkan clearance slip dari $\mathrm{BO}$ agar dapat mengetahui mahasiswa tersebut adalah mahasiswa yang terdaftar sebagai calon wisudawan.

c. Kemudian mahasiswa yang mengajukan calon wisudawan terlebih dahulu melihat buku pinjaman di Perpustakaan. Jika mahasiswa masih memiliki buku pinjaman dan belum dikembalikan ke Perpustakaan, maka mahasiswa yang mengajukan calon wisudawan tidak bias mendapat persetujuan dari Perpustakaan.

d. Lalu mahasiswa yang mengajukan calon wisudawan diharuskan ke Kantor Asrama untuk mengurus absensi asrama. Jika mahasiswa masih mendapatkan absensi yang belum diselesaikan, maka mahasiswa yang mengajukan calon wisudawan tidak bisa mendapat persetujuan dari Kantor Asrama.

e. Setelah itu mahasiswa bersangkutan diharuskan datang ke Kantor Biro Administrasi Akademi (BAA) untuk melakukan pengembalian KTM, Slip Bundel Skripsi, dan Lembar pengesahan Judul, Abstrak.

f. Kemudian mahasiswa yang mengajukan calon wisudawan diharuskan ke Kantor BAA untuk memberikan pas foto berwarna 3 × 4 sebanyak 4 lembar dan harus dicetak di kertas Doff/ kulit jeruk. 
g. Langkah terakhir, mahasiswa yang mengajukan calon wisudawan diharuskan ke Kantor BAA untuk melakukan berfoto menggunakan toga serta pemilihan ukuran toga.

\section{Analisa Permasalahan}

Seperti yang sudah dijelaskan pada latar belakang masalah oleh Biro Administrasi Akademik di Universitas Advent Indonesia (UNAI), maka dapat diindentifikasikan beberapa permasalahan sebagai berikut :

1. Cara pengolahan data pendaftaran calon wisudawan pada mahasiswa

2. Pegawai BAA yang masih manual untuk memproses data mahasiswa yang mengajukan pendaftaran calon wisudawan.

3. Mahasiswa masih kesulitan untuk mencari tanda tangan setiap dosen yang bersangkutan dikarenakan satu dan dua hal.

\section{Use Case Diagram}

Dalam peracangan sistem yang akan dibuat, maka penulis akan menggunakan use case untuk menggambarkan proses yang dilakukan. Berikut ini adalah gambar use case diagram dan keterangan user dari keterangan yang didapat dari Analisa kebutuhan sistem. Use Case ini memiliki 4 aktor yaitu Mahasiswa, Business Office, Perpustakaan, BAA.

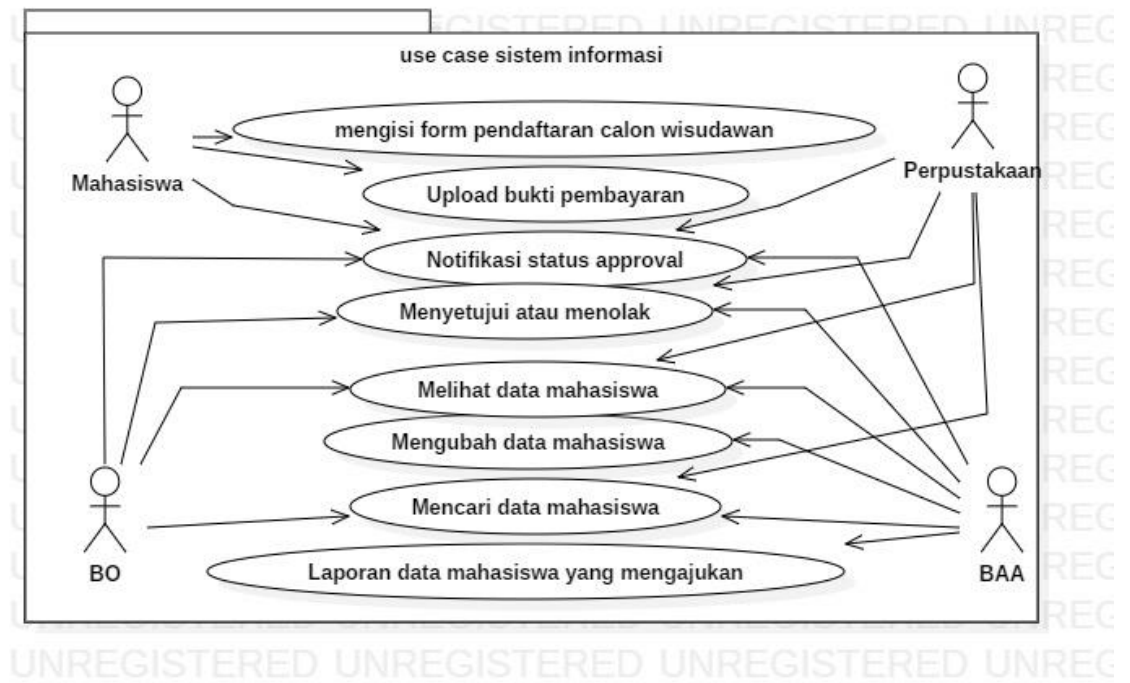

Gambar 1 Use Case Diagram

Dari gambar Use Case diagram di atas dapat dilihat dari user yang bisa melakukan bebrapa fungsi dari sistem yang diusulkan sebagi berikut.

1. Mahasiswa harus login untuk dapat melakukan pengajuan calon wisudawan seperti mengisi form pendaftaran calon wisudawan, melihat biodata mahasiswa, dan menerima notifikasi persetujuan.

2. Perpustakaan akan login terlebih dahulu untuk dapat melakukan pengecekan peminjaman buku serta pengembalian buku mahasiswa yang mengajukan calon wisudawan, menerima notifikasi utuk approval kepada mahasiswa yang mengajukan calon wisudawan, melihat biodata mahasiswa yang mengajukan calon wisudawan, dan melihat laporan wisudawan.

3. Biro Keuangan akan login terlebih dahulu untuk bisa melakukan approval kepada mahasiswa yang telah menyelesaikan keuangan, membayar uang wisuda, serta membayar uang senior. 
4. Biro Administrasi Akademik akan login terlebih dahulu untuk dapat melakukan pengecekan kelengkapan data mahasiswa yang mengajukan pendaftaran calon wisudawan, menerima notifikasi untuk approval kepada mahasiswa yang mengajukan pendaftaran calon wisudawan, melihat biodata mahasiswa yang mengajukan calon wisudawan, dan mengubah data mahasiswa.

\section{Activity Diagram}

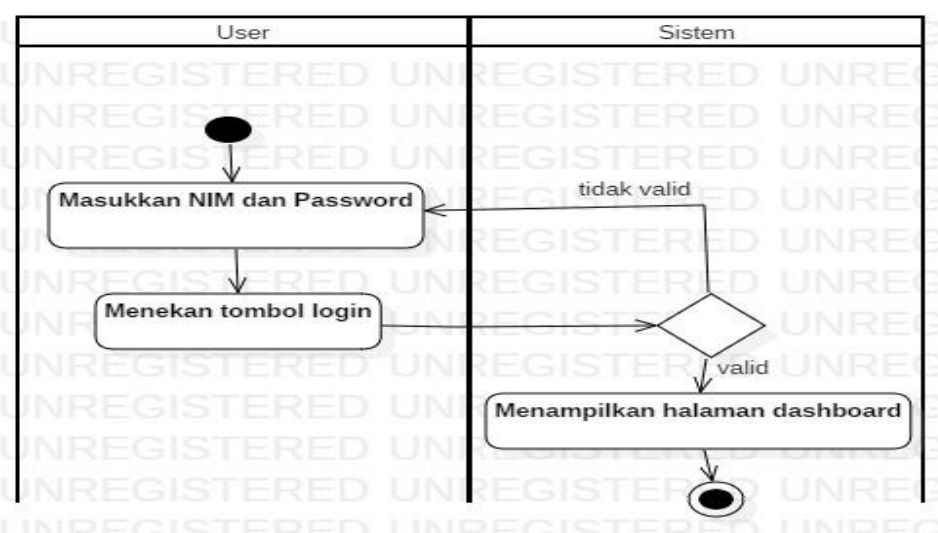

Gambar 2 Activity Diagram Login

Dari gambar Activity Diagram Login diatas, dapat dijelaskan bahwa, user sebelum masuk ke sistem tersebut, harus melakukan login yaitu input data nim dan password, setelah data di input data tersebut akan diproses oleh sistem apakah data yang dimasukan sudah benar atau tidak, apabila data tidak benar maka sistem akan memberitahukan.

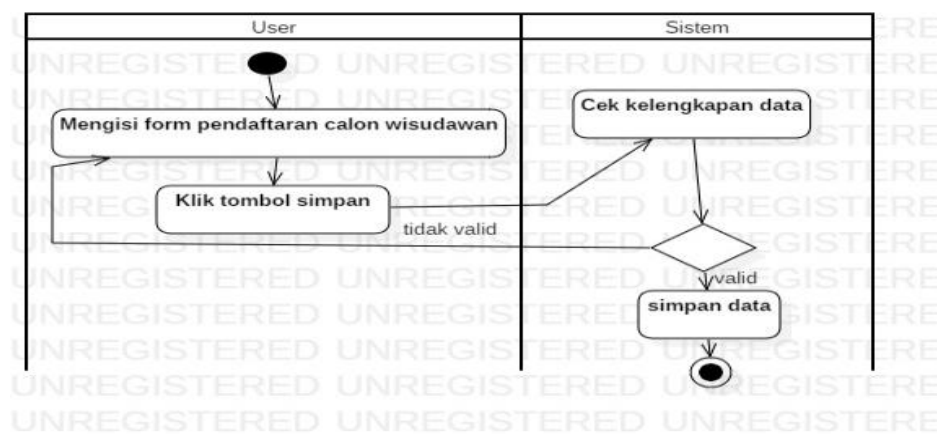

Gambar 3 Activity Diagram Mengisi Form Calon Wisudawan

Gambar di atas menjelaskan bahwa user yang akan melakukan pendaftaran calon wisudawan harus mengisi form yang sudah disediakan oleh sistem, setelah data diisi sistem akan mengecek apakah data sudah memenuhi syarat yang dibutuhkan. Setelah data berhasil di input selanjutnya data akan tersimpan di database. 


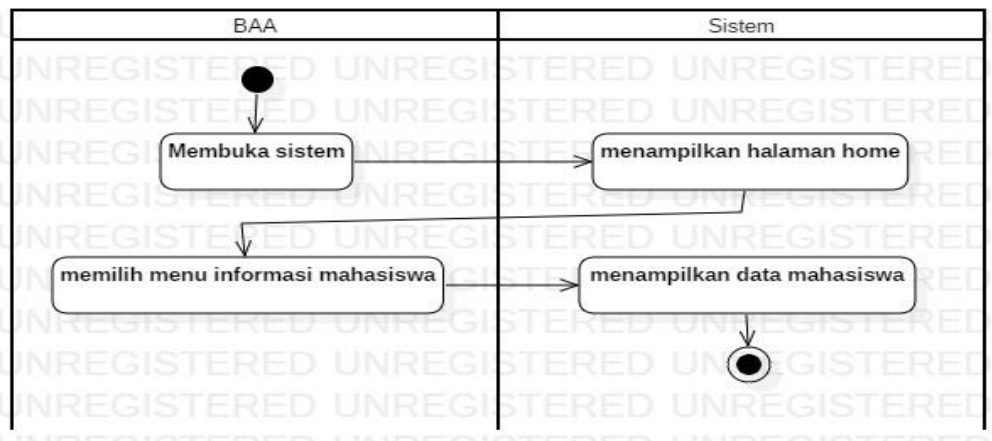

Gambar 4 Activity Diagram Melihat Data Mahasiswa Calon Wisudawan

Dari Gambar di atas menerangkan apabila BAA yang ingin melihat data calon wisudawan dapat melakukan terlebih dahulu login, lalu BAA akan memilih menu informasi mahasiswa. Selanjutnya sistem akan menampilkan data yang berhasil disimpan di database sehingga BAA dapat melihat berapa banyak yang sudah melakukan pendaftaran calon wisudawan.

\section{Class Diagram}

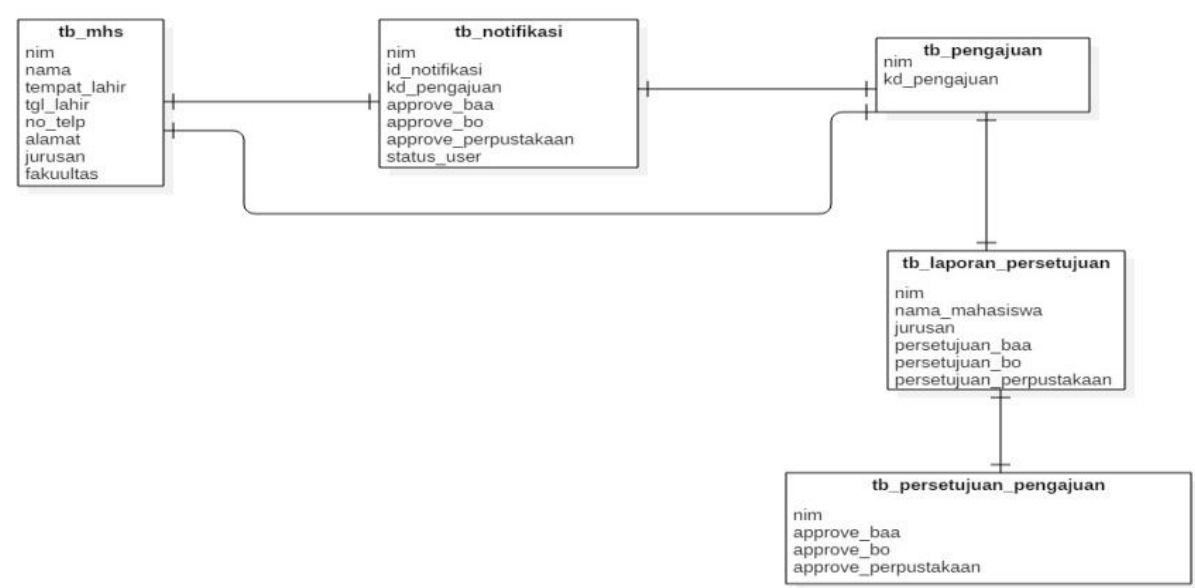

Gambar 5 Class Diagram

Gambar diatas menunjukkan tabel yang terdapat dalam Sistem Informasi Calon Wisudawan, dimana terdapat 5 tabel diantaranya adalah tabel mahasiswa, tabel notifikasi, tabel pengajuan, tabel laporan persetujuan dan tabel persetujuan pengajuan.

\section{Hasil}

Dalam proses pengembangan sistem informasi tersebut dengan tujuan yang akurat untuk membantu proses pendataan calon wisudawan pada Universitas Advent Indonesia agar berjalan lancar. Tampilan antar muka hasil perancangan sebagai berikut 


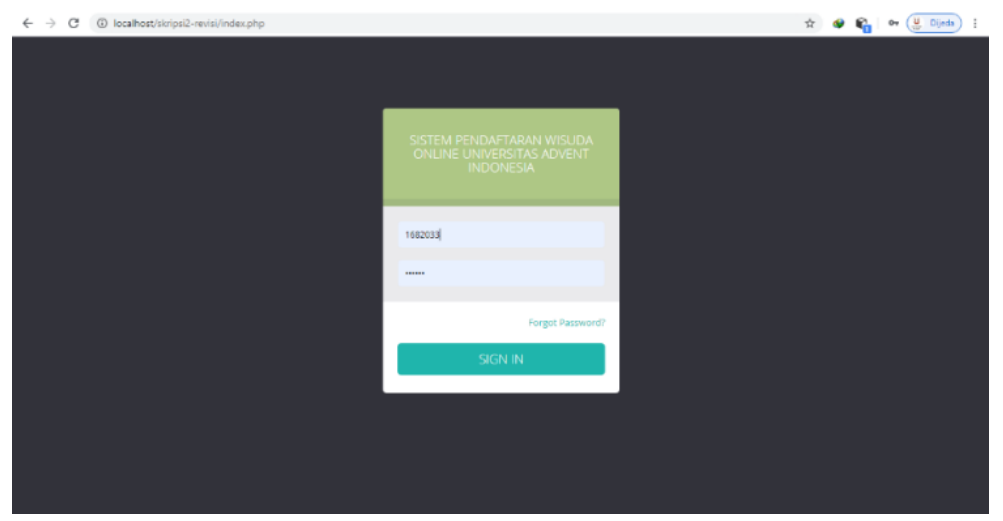

Gambar 6 Halaman Login

Gambar 6 merupakan halaman login dalam keadaan kosong. Di mana halaman login bertujuan untuk input nim dan password sebelum masuk ke tampilan dashboard. Jika nim dan password benar, maka akan dibawa ke halaman dashboard dan apabila nim dan password salah makan tidak bias masuk ke halaman dashboard.

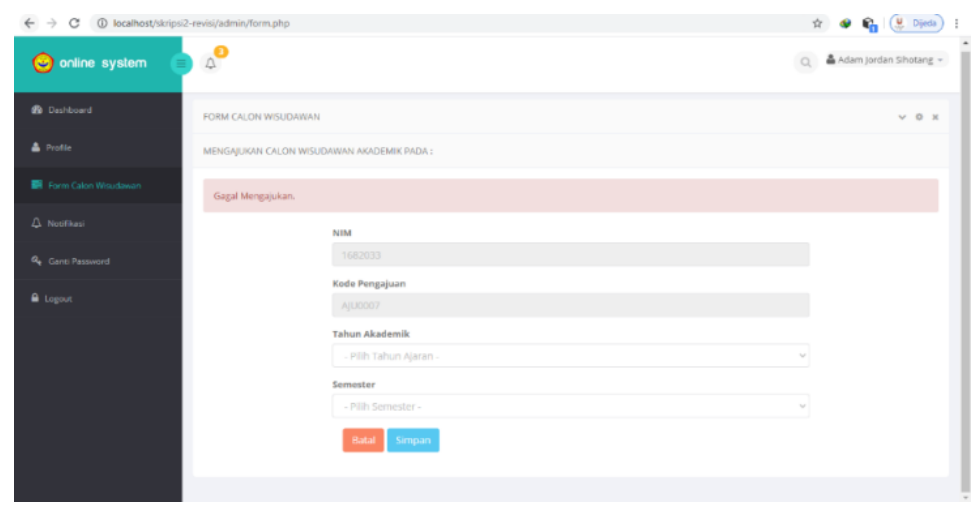

Gambar 7 Tampilan Halaman Form Calon Wisudawan

Gambar 7 merupakan tampilan halaman form calon wisudawan yang berisikan formulir yang harus diisi oleh mahasiswa bagi yang akan mengajukan pendaftaran calon wisudawan.

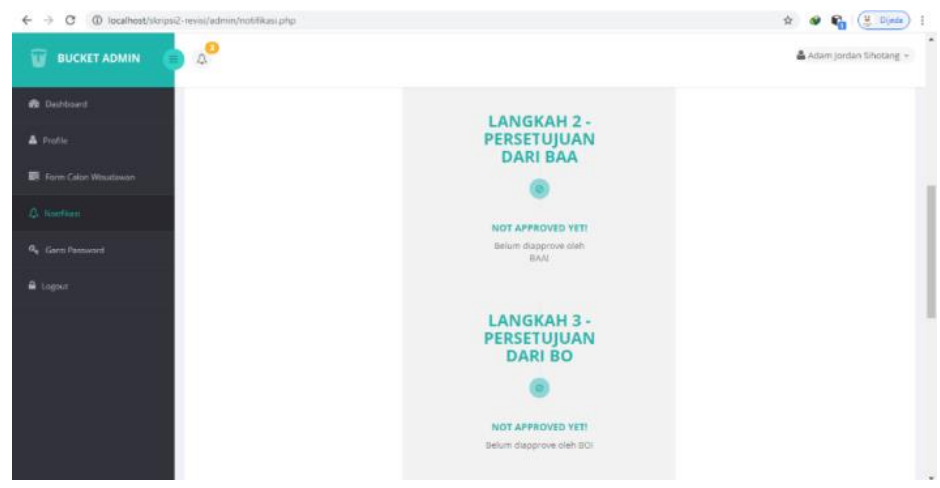

Gambar 8 Tampilan Halaman Notifikasi 
Gambar 8 merupakan tampilan halaman notifikasi yang berisikan informasi di mana calon wisudawan akan dapat melihat status pendaftaran calon wisudawan.

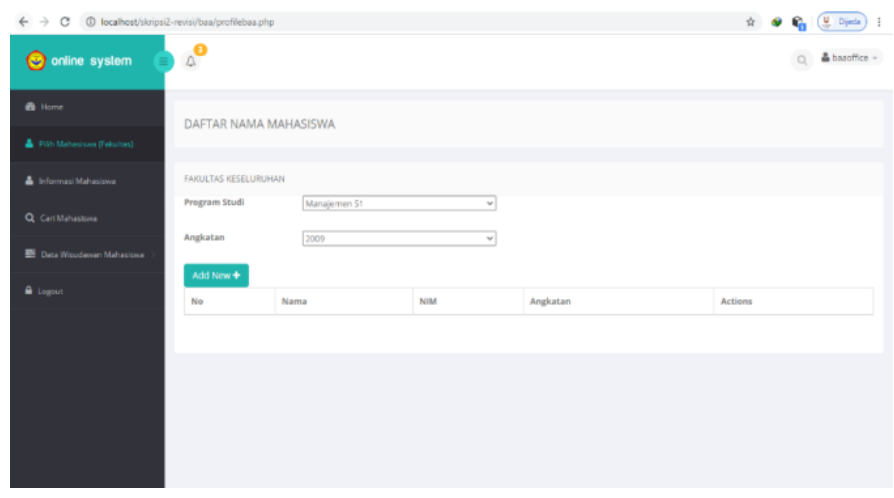

Gambar 9 Tampilan Halaman Pilih Mahasiswa

Gambar 9 merupakan tampilan halaman pilih mahasiswa yang berfungsi untuk mencari mahasiswa yang mendaftar sebagai calon wisudawan.

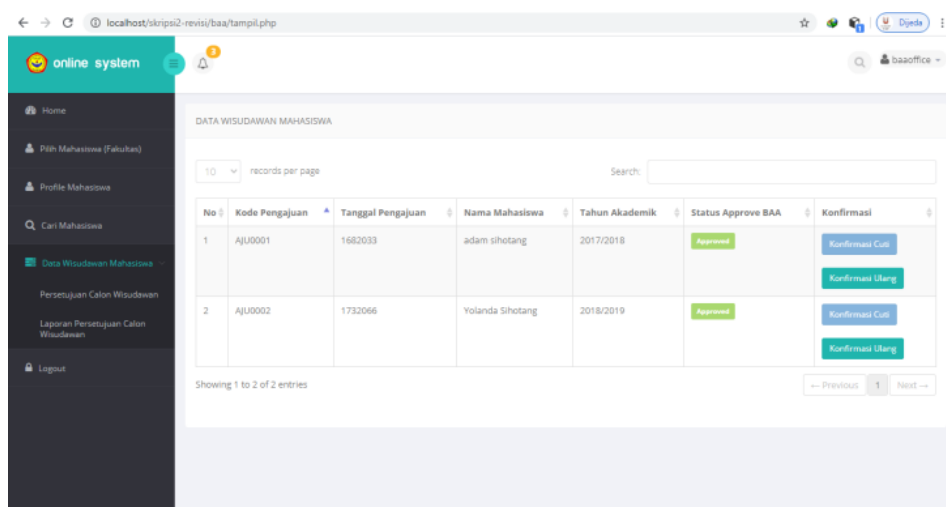

Gambar 10 Tampilan Halaman Persetujuan Calon Wisudawan

Gambar 10 merupakan tampilan halaman persetujuan calon wisudawan yang berfungsi sebagai data record dari setiap mahasiswa yang mengajukan pendaftaran calon wisudawan.

\section{Kesimpulan}

Berdasarkan penelitian yang telah dilakukan penulis mengenai perancangan sistem informasi calon wisudawan berbasib web, maka dapat diambil kesimpulan sebagai berikut :

1. Sistem informasi calon wisudawan ini dibuat dengan menggunakan Bahasa pemrograman PHP (Hypertext Prepocessor) dan MySQL sebagai databasenya yang terdiri dari home, pilih mahasiswa(fakultas), profile mahasiswa, cari mahasiswa, persetujuan calon wisudawan, laporan persetujuan calon wisudawan. Sedangkan untuk admin yakni halaman dashboard, profile, form calon wisudawan, notifikasi, ganti password, logout.

2. Setelah melakukan pengetesan terhadap sistem informasi ini, didapati bahwa proses pemasukan data calon wisudawan dapat dilakukan dengan baik. 
Adapun saran yang dapat penulis berikan pada penelitian ini adalah:

1. Untuk menjaga data-data ataupun sistem informasi ini, sebaiknya dilakukan back up data ke sistem penyimpanan lain dan sistem perawatan yang baik untuk menghindari adanya kerusakan sistem.

2. Dengan adanya sistem informasi ini, pemakai disarankan untuk memperhatikan kekurangan sistem agar dapat segera di cari pemecah masalahnya dan dilakukan pengembangan sistem untuk masa yang akan datang demi kelangsungan pelaksanaan sistem informasi yang baik.

3. Dengan adanya sistem informasi ini, penulis berharap aplikasi ini dapat di integrasikan ke modul Universitas Advent Indonesia.

\section{Daftar Pustaka}

[1] T. Astriani, Aplikasi Pembelajaran Pengenalan Kebudayaan Indonesia Berbasis Multimedia, Yogyakarta: Akakom, 2011.

[2] Lubis, A. (2016). Perancangan Sistem Informasi Usaha Ekonomi Kelurahan Simpan Pinjam (UEKSP) Mekaar Sari pada Lembaga Pemberdayaan Kelurahan Rejosari Pekanbaru Berbasis Web. Riau Journal Of Computer Sciense, Volume 2, No.1.

[3] Yasin., Feri. (2012). Rekayasa Perangkat Lunak Berorientasi Objek. JAKARTA: MITRA WACANA MEDIA

[4] Suryadinata, C., Brenda, M., \& Chindyana, M. (2016). Analisa Dan Perancangan Strategi EMarketing Menggunakan Responsive Web Design Berbasis Kerangka Kerja Sostac(R)Pada PT. GLORIA MANDIRI TRENDICOM. 